\title{
REFLEXÕES SOBRE A CRISE FINANCEIRA INTERNACIONAL E O ESTADO DE BEM-ESTAR ${ }^{1}$
}

REFLECTIONS ON THE INTERNATIONAL FINANCIAL CRISIS AND THE STATE OF WELL-BEING

REFLEXIONES SOBRE LA CRISIS FINANCIERA INTERNACIONAL Y EL ESTADO DE BIENESTAR

Maurizio Oliviero²

Paulo Márcio Cruz ${ }^{3}$

RESUMO

O presente artigo trata dos reflexos da atual crise financeira global nas estruturas do Estado de Bem-Estar europeu. A Europa que protege foi e é um lema da União Europeia. Todavia o Estado de Bem-Estar vem sofrendo críticas na Europa desde as décadas de oitenta e noventa do século passado. A atual situação de crise intensa abre possibilidade para questionamentos dos modelos existentes de Estado de Bem-Estar sob diversos ângulos, colocando dúvidas sobre a atual oportunidade e viabilidade do mesmo. O objetivo deste artigo é incitar a discussão acerca dos limites e do destino próximo do Estado de Bem-Estar frente à crise financeira internacional.

PALAVRAS-CHAVE: Estado de Bem-Estar. Crise Financeira Internacional. Europa. União Europeia.

\begin{abstract}
In the past five decades, Europeans have transformed high taxes into a protection net, which continues from the cradle to the grave. Europe that protects is the motto of European Union. Nevertheless, the Welfare State has been a subject of criticism in Europe since the 1980s. The current situation of intense crises opens the existing model of Welfare State opening to questioning, under different viewpoints, raising doubts as to the current opportunity and viability of this State model. The objective of this paper is to promote discussion on the limits and the near future of the Welfare State in the face of the international financial crisis.
\end{abstract}

KEYWORDS: Welfare State. International Financial Crisis. Europe. European Union.

1 O presente trabalho é fruto das reflexões e dos debates efetuados pelos professores doutores Paulo Márcio Cruz e Maurizio Oliviero durante a estada do segundo na UNIVALI, no Programa de Pós-Graduação Stricto Sensu em Ciência Jurídica - PPCJ/UNIVALI, cursos de Mestrado e Doutorado, como Professor Estrangeiro Visitante, com bolsa da Fundação Coordenação de Aperfeiçoamento de Pessoal de Nível Superior (CAPES), de março de 2011 a outubro de 2012.

2 Doutor em Direito e Catedrático da Faculdade de Direito da Universidade de Perugia. Titular das disciplinas de Direito Público Comparado e Direito Islâmico. Professor visitante com bolsa CAPES no Programa de Pós-Graduação Stricto Sensu em Ciência Jurídica - Cursos de Mestrado e Doutorado, professor visitante e pesquisador em diversas universidades (Columbia University, Al-Quds de Jerusalém e Heildelberg, Alemanha - Max Planck Institut e Universidade de Alicante na Espanha. Embaixador do Programa Erasmus pela Itália. (oliviero@unipg.it).

3 Pós-Doutor em Direito do Estado pela Universidade de Alicante, na Espanha, Doutor em Direito do Estado pela Universidade Federal de Santa Catarina e Mestre em Instituições Jurídico-Políticas também pela Universidade Federal de Santa Catarina - UFSC. Coordenador e professor do Programa de PósGraduação Stricto Sensu em Ciência Jurídica da Universidade do Vale do Itajaí - UNIVALI em seus programas de Doutorado e Mestrado em Ciência Jurídica. Foi Secretário de Estado em Santa Catarina e Vice-reitor da UNIVALI. É professor visitante nas universidades de Alicante, na Espanha, e de Perugia, na Itália. (pcruz@univali.br). 
El presente artículo trata sobre los reflejos de la actual crisis financiera global en las estructuras del Estado de bienestar europeo. La Europa que protege fue y es un lema de la Unión Europea. Sin embargo, el Estado de bienestar viene sufriendo críticas en Europa desde las décadas del ochenta y del noventa del siglo pasado. La actual situación de crisis intensa abre la posibilidad de cuestionar los modelos existentes de Estado de bienestar desde diversos ángulos, planteando dudas acerca de la actual oportunidad y viabilidad del mismo. El objetivo de este artículo es incitar al debate acerca de los límites y del destino próximo del Estado de bienestar frente a la crisis financiera internacional.

PALABRAS CLAVE: Estado de bienestar. Crisis Financiera Internacional. Europa. Unión Europea.

\section{PARA COMEÇAR: NOTAS DE INTRODUÇÃO}

A América Latina sempre enxergou os estados de bem-estar europeus com admiração e com uma indisfarçável vontade de ter o mesmo modelo em seus países. Tem sido o sonho dos latino-americanos quando se discute qual o modelo ideal de Estado. Nas últimas décadas o Estado de Bem-Estar foi sobejamente discutido nos meios acadêmicos como um modelo a ser seguido.

De maneira até inusitada, a crise iniciada em 2008 coloca em xeque o modelo de Estado ou, pelo menos, gera questionamentos profundos sobre sua viabilidade a médio e longo prazo.

Os especialistas economistas assistem atônitos, com a sua ciência mais inexata do que nunca, à crise que começou nos Estados Unidos e vem derretendo os ativos financeiros, os empregos e a credibilidade de todo sistema econômico da Europa, com gravíssimas repercussões na vida do cidadão comum. Aquele cidadão que acreditou - e ainda acredita - ser seu modo de vida o mais adequado para as nações de nosso planeta.

Na verdade, em toda a Europa Ocidental, o estilo de vida europeu está em debate. O mundo todo sempre admirou os europeus por seu sistema de benefícios sociais e por seus sistemas de saúde pública. Enfim, por seu modelo de bem-estar social em contraste com a dureza do jogo de mercado noutros países "capitalismocêntricos", já pedindo desculpas pelo neologismo.

Os europeus, ao longo das últimas cinco décadas, transformaram impostos altos em uma rede de proteção que vai do berço à sepultura. A Europa que protege é um lema da União Europeia. Mas todos os governos da Europa com grandes orçamentos, receitas fiscais em queda e envelhecimento da população enfrentam o aumento do deficit público e o endividamento privado - e outras notícias ruins produzidas pela crise financeira.

Na Grécia, por exemplo, país atingido em cheio pela crise, a sociedade ressente-se de pagar impostos elevados para financiar um estado inchado e de eficiência duvidosa. Reverbera a antiga discussão entre a função pública, na qual seus membros chegam a se aposentar aos 50 anos com altos salários, enquanto aqueles que estão na iniciativa privada, pela forma como as coisas estão caminhando, terão de trabalhar até chegar aos 70. Em toda Europa existem questionamentos sobre qual será o futuro daqueles que dependem ou dependerão da assistência do Estado. Os cidadãos com idades próxima da aposentadoria estão profundamente pessimista em relação à consecução desse objetivo. Para esse cidadão, o governo está tergiversando sobre a solução aos graves problemas que atingem a população e não acredita que haverá condições de encher os cofres da previdência. A frase mais ouvida é a de que "o país não tem futuro".

Entretanto se acredita que a perplexidade que toma conta da Europa Ocidental poderia ser amenizada com a retomada do debate sobre o novo papel do Estado de Bem-Estar ${ }^{4}$, que contestou a concepção liberal de que a liberdade e o desenvolvimento das atividades privadas só podem ser garantidos por meio da limitação das funções do Estado.

4 Estado de Bem-Estar é sinônimo de Estado Social Democrata ou simplesmente Estado Social, que são denominações diferentes para um mesmo modelo ideológico de Estado, cada um deles com algumas características próprias, como será visto mais adiante. 
Considerando as experiências ocorridas nos países ocidentais, pode-se dizer que a transformação dos Estados liberais em Estados de Bem-Estar implicou uma ruptura de determinados aspectos da ordem jurídica e econômica até então existente.

Diante dessa realidade, o Estado passou a chamar para si a solução dos problemas sociais emergentes, principalmente por meio de sua principal característica: a intervenção direta nos domínios econômico, social e cultural.

Pode-se entender por Estado de Bem-Estar uma determinada concepção de conformação estatal, baseada na intervenção social e econômica que levaram a efeito alguns Estados liberal-democráticos contemporâneos. Uma análise da evolução do Estado Moderno mostra diversas experiências de intervenção social, econômica e - mais recentemente - cultural, do Estado5.

O Estado de Bem-Estar é, na verdade, uma adaptação do Estado burguês capitalista, ou seja, dos regimes baseados na Democracia pluralista. A plena articulação do Estado de Bem-Estar só pode funcionar com base em dois fundamentos do Estado liberal-democrático contemporâneo. Em primeiro lugar, as propostas do Estado de Bem-Estar tiveram como intenção garantir a acumulação capitalista mediante a intervenção sobre a demanda - com a intenção de manter a estabilidade social. Em segundo lugar, o Estado de Bem-Estar proporcionou uma nova e importante dimensão à Democracia, a partir do reconhecimento de um conjunto de direitos sociais ${ }^{6}$.

Por meio do constitucionalismo social, o Estado de Bem-Estar passou a desenvolver ações acompanhadas de uma crescente inclusão nas Constituições, não só de previsões de regulação estatal das relações contratuais, mas também de comandos aos poderes públicos para que passem a prover ou a financiar uma série de prestações de serviços, em geral públicos e gratuitos, aos cidadãos. Os esforços para garantir a igualdade de oportunidades - que, frise-se, é o objetivo principal do Estado de Bem-Estar - e distribuição de renda derivada de algumas ações do próprio Estado, completaram esta nova dimensão da Democracia que este modelo ideológico de Estado representa ${ }^{8}$.

Portanto, principalmente em algumas matérias, o Estado de Bem-Estar - ou os poderes públicos passou a prestar serviços diretamente à população, como nas já aludidas áreas da saúde, da educação, da habitação e, principalmente, a da seguridade - ou da previdência - social, como aposentadorias, auxílio-velhice, salário-desemprego, afastamentos remunerados para tratamento de saúde, pensões, etc. Estas foram as ações por meio das quais o Estado de Bem-Estar materializou-se e, a bem da verdade, resolveu boa parte dos problemas sociais nos países onde foi implantado de forma decidida. A doutrina costuma dizer que o Estado de Bem-Estar se caracteriza por ser fortemente ativo com as classes passivas, e passivo com as classes ativas, numa alusão a pobres e ricos, nesta ordem.

Esta tendência foi acompanhada também, por óbvio, de um aumento da carga tributária nestes países. As elites, diante da ameaça real do Comunismo instalado na extinta União Soviética, principalmente após a Segunda Guerra Mundial, quando aquele regime ganhou força tecnológica e bélica, resolveram pagar esta conta, que não foi pequena, mas que valeu a pena, em todos os casos, para aquelas elites. Foi mais ou menos no sentido do "entregar os anéis para não perder os dedos".

Com o fim da União Soviética, no final da década de oitenta, esta tendência foi progressivamente freada, quando não invertida, pelo movimento ideológico denominado Neoliberalismo, que será tratado em capítulo próprio mais adiante.

Os estudiosos do Estado de Bem-Estar vêm utilizando como indicador, de maneira a estabelecer a intensidade do Estado de Bem-Estar em um determinado país, o nível de gasto público e, em particular, de gasto com o setor social. Este indicador se apresenta como um percentual sobre o conjunto da riqueza produzida pelo país (Produto Interno Bruto - PIB). Na maioria dos países que adotam este modelo de Estado, o conjunto do gasto público, nas décadas de 70 e 80, chegou a representar entre 40 a $50 \%$ do PIB. ${ }^{9}$ Em alguns países, como os escandinavos, tidos como exemplos de Estado de Bem-Estar, chegou a 50\%.

5 Conforme Ernest FORSTHOFF, em sua obra Por uma reconstrução da doutrina europeia sobre o uso conceitual do termo e natureza do estado social de direito. p. 123.

6 SÁNCHES, Jordi et al. Manual de ciencia política, p. 336.

7 CRUZ, Paulo Márcio. Fundamentos do direito constitucional, p. 202.

8 BONAVIDES, Paulo. Do estado liberal ao estado social, p. 186.

9 GIORGIS, Andreas in Dizionario di Diritto Pubblico, p. 1905. 
A consequência desse movimento foi o sobrestamento de muitos dos dogmas liberais, com o Estado, antes considerado um mal necessário, passando a ser um elemento fundamental a todos os setores sociais, inclusive para aqueles que se opunham à sua intervenção ${ }^{10}$.

\section{PARA DESENVOLVER: O ESTADO DE BEM-ESTAR E ALGUMAS ABORDAGENS IMPORTANTES}

Estado de Bem-Estar é o sistema político-econômico que, mantendo um âmbito privado capitalista, encarrega o Estado de tarefas relativas à obtenção de condições sociais mínimas, como foi visto acima.

Esse conceito de Estado de Bem-Estar tem suas origens históricas nos segundo e terceiros quartos do Século XX, caso se aceite a premissa de que sua plena consolidação foi produzida após a Segunda Guerra Mundial. Em muitas ocasiões o seu conceito foi utilizado como sinônimo de "Estado Social". Alguns autores, como Wolkmer ${ }^{11}$, usam indistintamente ambos os termos. Outros, de acordo com o âmbito cultural no qual foram formados (nórdico ou anglo-saxão), utilizam as expressões "Estado Social" ou "Estado Social-Democrata" para definir categorias similares, senão iguais.

É possível apontar alguns aspectos diferentes entre ambos. Em primeiro lugar é preciso observar que o Estado Social é o modelo por meio do qual se concretiza a vontade de intervenção social dos organismos públicos, mesmo considerando que tanto o Estado de Bem-Estar quanto o Estado Social tenham reconhecimento constitucional. O que ocorre é que o nível de intervenção é diferente. Em segundo lugar, é comum utilizar-se o conceito de Estado de Bem-Estar para referir-se a âmbitos de intervenção pública que são menores que os incluídos no conceito de Estado Social.

A ação interventora e reguladora do Estado em matéria econômica e trabalhista, no que se refere à política salarial, pode-se dizer que é uma característica do Estado Social, mas que não faz parte dos objetivos primordiais do Estado de Bem-Estar.

É a partir dos anos 40, na Inglaterra, que são firmados e explicitados os princípios fundamentais do Estado de Bem-Estar. Em 1939, Alfred Zimmern, catedrático em Oxford, contrapôs welfare a power, numa clara intenção de diferenciar os regimes democráticos dos fascistas que por aquela época estavam em plena expansão no continente. O Estado de Bem-Estar, segundo a doutrina inglesa daquela década, deveria garantir a todos os cidadãos, independente de sua renda, a proteção de direitos sociais relacionados ao trabalho, à previdência, à saúde, à maternidade e à educação.

$\mathrm{O}$ fato de o uso do conceito de Estado de Bem-Estar ter origem acadêmica constituiu-se numa razão a mais para se prestar uma atenção especial às primeiras manifestações de concretização política da dimensão social do Estado.

A profunda crise estrutural da Sociedade e do Estado verificada entre as duas grandes guerras tem sido considerada a responsável pela exaustão completa do modelo liberal clássico. Neste período entre os dois conflitos mundiais, muitas transformações foram operadas. Neste sentido, como assinala Touchard, houve o desaparecimento do dualismo entre Estado e Sociedade e se manifestam abertamente os fatores que representavam para o Estado a transformação das capacidades e das condições da existência individual. ${ }^{12}$

O avanço mais importante, entretanto, foi representado pela constituição do Estado como Estado Social, em resposta direta às necessidades substanciais das classes subalternas emergentes. Assistiu-se, portanto, no período entre guerras, principalmente, a uma retomada por parte do Estado e do seu aparelho, de uma função de gestão direta da ordem social, mas, sobretudo, da ordem econômica, cujo andamento natural era agora posto em dúvida pela menor homogeneidade de classe da Sociedade Civil e pela impossibilidade de um controle automático e unívoco do próprio Estado por parte desta mesma Sociedade.

O Bem-Estar voltou a ser o objetivo mais prestigioso da gestão do poder, embora não mais em função declaradamente fiscal e político-econômica, como nos tempos do Estado Absoluto, e sim em

10 DALLARI, Dalmo de Abreu. o futuro do estado, p. 136.

11 WOLKMER, Antônio Carlos. Elementos para uma crítica do estado, p. 72.

12 TOUCHARD, Jean. Historia de las ideas políticas, p. 489. 
vista de um progressivo e indefinido processo de integração social ${ }^{13}$.

Este momento de surgimento de novas formas de prestação social a partir do Estado ou, preferindo, de ruptura com as políticas assistenciais próprias do Estado Liberal clássico, pode ser considerado como o início de um processo dinâmico de ajuste entre o indivíduo e o Estado. Um dos eixos principais de tal processo foi o surgimento da seguridade social em todas suas formas, fato que ajuda sobremaneira na análise científica dos diversos modelos possíveis do Estado de Bem-Estar.

Interessante ressaltar que, assim como o que se observa na atual crise europeia, o principal sintoma de esgotamento do modelo liberal clássico, durante as três primeiras décadas do século XX, foi o aumento acelerado do desemprego. O Estado passou a patrocinar políticas que garantissem a preservação dos postos de trabalho. O próprio Estado passou a ser um empregador em grande escala, principalmente com o crescimento do contingente de funcionários públicos dedicados aos serviços sociais, resposta a uma demanda social cada vez maior. O Estado de Bem-Estar transformase num elemento importante na resolução do problema do desemprego ${ }^{14}$.

Os economistas britânicos foram os responsáveis pela formulação econômica do Estado de BemEstar. A política econômica e social correspondente ao Estado de Bem-Estar corresponde às posições de John Maynard Keynes e seus seguidores ${ }^{15}$.

Podemos dizer que depois de Adam Smith e Thomas Malthus, economistas da escola clássica, e de Karl Marx, nenhum outro teórico foi tão importante quanto Keynes, pensador de muita influência na renovação das teorias econômicas tradicionais e na reformulação da política econômica do livre mercado.

A necessidade de alavancar o crescimento econômico e a extensão de um maior bem-estar para toda a Sociedade é considerada princípio indissociável que se vincula à crescente intervenção do Estado e que está ligado, de forma inequívoca, a Keynes.

Numa leitura sistematizadora do postulado de Keynes, é possível dizer que ele defendeu seu conceito de "multiplicador de demanda" como sendo a regra por meio da qual o aumento dos gastos governamentais aumenta a demanda agregada, o que criaria uma otimização do trabalho e do capital numa escala tal que a produção se expandiria em proporção superior ao crescimento daqueles gastos.

Considerando-se estas análises, pode-se dizer que a "equação keynesiana" apoiou a possibilidade de se fazer convergir elementos de mercado e sociais por meio da articulação de políticas redistributivas.

Numa perspectiva histórica, parece evidente que a pregação de Keynes, como modelo que pretendeu promover a combinação de recursos entre o mercado e o Estado converteu-se, até fins dos anos setenta, numa doutrina econômica que quase ninguém questionava, na medida em que sua defesa se relacionava estreitamente com a construção do Estado de Bem-Estar e permitia que este desfrutasse de um amplo consenso.

A obra de Keynes foi plenamente reconhecida em seus últimos anos de vida. Em 1944, chefiou a delegação do Reino Unido à Conferência de Bretton Woods ${ }^{16}$, nos Estados Unidos.

O modelo keynesiano, independentemente de sua consistência teórica, contou com vários elementos que ajudaram a torná-lo uma unanimidade nos mais diversos setores sociais e ideológicos. ${ }^{17}$ Uma das expressões mais visíveis deste fato foi o desaparecimento das disputas entre as classes sociais que convulsionaram as sociedades capitalistas nos períodos anteriores à II Guerra Mundial, o que pode ser atribuído a dois fatores:

13 BOBBIO, Norberto et al. Dicionário de política, p. 430.

14 NAVARRO, Vicenç. Neoliberalismo y estado de bienestar, p. 107.

15 VERDÚ, Pablo Lucas; MURILLO DE LA CUEVA, Pablo. Manual de derecho político, p. 120.

16 Quando a guerra aproximava-se do fim, a Conferência de Bretton Woods foi o ápice de dois anos e meio de planejamento da reconstrução pós-guerra pelos Tesouros dos EUA e Reino Unido. Representantes estadunidenses estudaram com os colegas britânicos a reconstituição do que tinha estado faltando entre as duas guerras mundiais: um sistema internacional de pagamentos que permitisse que o comércio fosse efetuado sem o medo de desvalorizações monetárias repentinas ou flutuações selvagens das taxas de câmbio - problemas que praticamente paralisaram o capitalismo mundial durante a Grande Depressão.

17 KING, Anthony; SCHNEIDER, Benton. Teoria política en el Estado de Bien-Estar, p. 136. 
a) o crescimento econômico que as sociedades ocidentais experimentaram a partir dos anos cinquenta; e

b) a extensão do Bem-Estar social a camadas cada vez mais amplas da Sociedade.

O Estado de Bem-Estar passou a gozar de um enorme grau de consenso, assim como as políticas econômicas keynesianas.

Nas duas décadas após a II Guerra Mundial havia uma sensação de que, efetivamente, a consolidação e a expansão do Estado de Bem-Estar correspondiam, na realidade, a um período que poderia significar o fim do confronto ideológico entre esquerda e direita ou entre liberdade e igualdade. O decurso dos acontecimentos, porém, mostrou o equívoco desta percepção.

De qualquer forma, em qualquer destas direções, as pesquisas disponíveis são suficientemente amplas para uma abordagem sistemática sobre este assunto. Um bom exemplo de coincidência que se pode encontrar nos estudos sobre o Estado de Bem-Estar é a que tem o gasto público como principal hipótese de pesquisa, critério muito utilizado até por conta da falta de dados para operar com outras hipóteses.

Um dos traços permanentes nos textos que tratam deste tema é que a maioria das abordagens que se limitam à analise do Estado de Bem-Estar a partir dos investimentos públicos, consideram que todo gasto realizado pelo Estado tem o mesmo valor, independente dos seu fins e dos seus resultados.

Assim, as diferenças que devem ser apreciadas entre os diversos modelos de Estado de BemEstar possibilitam a elaboração de distintas classificações, como a classificação já clássica realizada por Titmuss, que distinguiu dois modelos: a) o residual, no qual o Estado desempenha uma função mínima na provisão do bem-estar, cujos serviços são de escassa qualidade e destinam-se à subsistência, ao contrário do mercado e da família, que são as instituições que gozam de maior relevância; b) o institucional que, diferente do anterior, tem o Estado como principal instrumento para a provisão do bem-estar ${ }^{18}$.

O britânico Richard Titmuss ${ }^{19}$ é uma das principais referências contemporâneas e que se dedicou à investigação das políticas sociais e do Estado de Bem-Estar em suas múltiplas formas e efeitos.

Os modelos ditos "institucionais" se caracterizariam pela universalidade dos serviços prestados, ou seja, com os serviços atendendo a toda Sociedade de forma indistinta. Nesta forma de organização, o Estado assume um papel de intervenção com o objetivo de assegurar um mínimo de bem-estar em todos aqueles âmbitos considerados imprescindíveis ao conforto individual.

Naqueles ditos "residuais", ao contrário, a intervenção somente aconteceria quando falhassem os instrumentos preceptores - a família e o mercado - para a realização do bem-estar. Neste caso, a intervenção ficaria limitada a segmentos bem delimitados e praticamente excluídos da Sociedade.

A diferença básica entre estes dois tipos de Estado de Bem-Estar está no fato de que, nos "institucionais", os direitos sociais para a cidadania ocupam um espaço central, enquanto que, nos ditos "residuais", os direitos estariam sujeitos a provas de merecimento por critérios de carência social.

Para se ir além do critério do estrito conhecimento do gasto público para classificar o Estado de Bem-Estar, deve-se ter em conta, então, a análise dos programas de intervenção do Estado em diversas políticas sociais. Aspectos como as condições para desfrutar das ações que oferecem os programas, universalidade e especificidade de alguns destes programas ou qualidade das transferências econômicas previstas nos mesmos são questões relevantes que devem ser consideradas quando se pretende aprofundar o debate sobre o Estado de Bem-Estar.

O Estado de Bem-Estar gozou de um amplo consenso desde os anos quarenta até os anos setenta, durando, mais especificamente, até a crise econômica de 1973, que abalou os princípios keynesianos e sobre os quais havia se sustentado. A partir desta crise, o consenso do pós-

18 BLAS GUERRERO, Andrés \& VERDÚ, Jaime Pastor. Fundamentos de ciência política, p. 117.

19 RICHARD MORRIS TITMUSS (1907-1973), um dos maiores e mais respeitados estudiosos do Estado de Bem-Estar do Ocidente e um dos seus mais influentes teóricos na Grã-Bretanha, foi professor do London School of Economics de 1950 até sua morte, em 1973. Escreveu, entre outras obras, The philosuphy of welfare: selected writings of Richard M. Titmuss, Commitment to Welfare, Essays on "the welfare state", Social policy: an introduction, Problems of Social Policy e Unequal rights. 
guerra em torno da economia mista e do Estado-Providência, partilhado, sofreu seu primeiro importante revés ${ }^{20}$.

A fase de pujança econômica iniciada após a II Guerra Mundial chegou ao fim por conta de dois fatos marcantes. O primeiro deles foi a decisão dos Estados Unidos de não manter a convertibilidade do dólar em ouro, tomada em virtude da quantidade da moeda norte-americana em circulação em outros países ${ }^{21}$. Os problemas econômicos causados por esta decisão se prolongaram desde meados da década de setenta até o início da de oitenta. Diante desta nova realidade econômica, os países ocidentais começaram a ter sérias dificuldades para continuar implementando suas políticas econômicas baseadas no modelo keynesiano.

Importante ressaltar, no entanto, que a crise econômica de 1973 não foi a única responsável pelo questionamento ao modelo keynesiano. O segundo fato marcante foi o crescimento descontrolado do gasto público. Este fato, importante lembrar, é um dos grandes - se não o principal - problemas de países europeus, que se debatem entre a pressão de seus cidadãos para manter os benefícios do Estado de Bem-Estar e as exigências do Banco Central Europeu e do FMI para que controlem o déficit público, aumentem a carga tributária e para que o Estado abandone a intervenção em diversos setores, principalmente o social.

Está-se falando de uma época em que a Europa estava em estágio inicial de sua integração econômico-financeira.

Hoje a realidade é outra. Os governos atuais, na Europa, engessados pela gestão centralizada do euro, passam a ter que conviver com a contradição de manter os altos custos do Estado de BemEstar e aumentar a carga tributária ou reduzir os investimentos públicos que beneficiavam milhares de pessoas. ${ }^{22} \mathrm{Em}$ qualquer dessas situações, a impopularidade e o possível desgaste eleitoral são fantasmas sempre presentes.

A intervenção do Estado para regular a economia, que havia sido a prática característica do modelo keynesiano para fazer frente, respectivamente, ao crescimento da estagnação ou ao da inflação, mostrara-se ineficiente para combater a atual crise na Europa.

Com o desequilíbrio fiscal e o aumento da recessão e do desemprego, verificado, principalmente, nos países da periferia europeia, a estrutura pública de Estado de Bem-Estar ficou ainda mais vulnerável.

As novas orientações são no sentido de que os governos não devem manter as políticas voltadas para o pleno emprego, já que isto criaria efeitos indesejáveis, como o aumento da inflação e a diminuição da produtividade.

Será muito difícil manter a base ideológica e política do Estado de Bem-Estar diante da onda conservadora e tecnocrata que assola o Ocidente europeu. Pode-se dizer que os principais serviços universais - manutenção dos rendimentos, cuidados de saúde e educação - terão grandes dificuldades para sobreviverem ao movimento neoconservador na Europa Ocidental.

O Estado de Bem-Estar vem sofrendo críticas na Europa desde as décadas de oitenta e noventa do século passado. A atual situação de crise intensa abre possibilidade para questionamentos dos modelos existentes de Estado de Bem-Estar sob diversos ângulos, colocando dúvidas sobre a atual oportunidade e viabilidade do mesmo. De forma ampla, as críticas correspondem a três posturas ideológicas distintas e, dependendo do tema em discussão, opostas: o neoliberalismo, o neoconservadorismo e a neotecnocracia (se é que se pode chamar assim), esta última representada por correntes reformistas, como aquela representada pelo Premiê Mario Monti, na Itália23.

As pregações neoconservadoras giram em torno, principalmente, de movimentos políticos e econômicos destinados a diminuir o Estado Médio de Bem-Estar para a condição de um Estado capaz de enfrentar a atual crise econômica na Europa e insistem em dois fenômenos para sustentar esta "nova" proposta de atuação política, econômica e estatal:

20 MISHRA, Ramesh. 0 estado-providência na sociedade capitalista, p. 05.

21 BLAS GUERRERO, Andrés; VERDÚ, Jaime Pastor. Fundamentos de ciência política, p. 119.

22 CRUZ, Paulo Márcio; REAL, Gabriel. Los nuevos escenarios transnacionales y la democracia asimétrica, p. 12-17.

23 CRUZ, Paulo Márcio. Da Soberania à Transnacionalidade: Democracia, Direito e Estado no Século XXI, p. 76. 
a) a Crise de Governabilidade, originada por uma ideologia igualitária que tende a "deslegitimar" a autoridade política, por meio de uma intervenção do Estado que não pretendia outra coisa senão corrigir efeitos sociais perversos causados pelo passado Liberalismo. A disposição do Estado de intervir nas relações sociais provoca um enorme aumento nas solicitações dirigidas às instituições políticas, determinando a sua paralisia pela sobrecarga de demanda. As bases de sua crítica se situam no corolário de que o Estado não pode assimilar uma demanda por serviços públicos e gratuitos ilimitada por parte da Sociedade; e

b) a Sobrecarga do Estado a partir de concepções pluralistas da Sociedade, que se compõe de múltiplos grupos, cujos interesses são objeto de negociação e compromisso com o Poder. Estes grupos trabalham com uma expectativa cada vez mais elevada para o seu nível de vida. O sistema de disputa entre os grupos de pressão e as agremiações políticas obriga o governo a assumir vários compromissos, mesmo que contraditórios, para se manter no Poder. Assim, os governos não possuem autoridade suficiente para impor o que se poderia denominar de um adequado ajuste econômico. As tentativas feitas pelos governos para ter maioria nos parlamentos implicaram ampliar ao extremo o exercício da negociação, deturpando a concepção de Democracia. O resultado desta falta de "correções periódicas de rumo" acaba por formar um círculo vicioso do qual o Estado de Bem-Estar, após determinado período, torna-se refém.

O Neoconservadorismo é o principal movimento de oposição aos modelos de Estado de BemEstar observado na atual crise. O Estado de Bem-Estar e a Democracia Social, por extensão, são, para a Neoconservadorismo, incompatíveis com a ética e a liberdade política e econômica.

Contra o Estado de Bem-Estar existem, atualmente, argumentos muito robustos e não são poucos nem de pouca intensidade. Os neoconservadores, aliados muitas vezes aos neoliberais (e até mesmo a liberais ortodoxos), mesmo ressalvadas as discordâncias que se possa ter em relação aos seus argumentos, expõem contradições muito concretas em suas críticas.

Muito do que se pode ler sobre a grave crise pela qual atravessa a Europa permite apontar essas contradições, sendo possível resumir aquelas que seriam as mais relevantes e as que mais têm tido efeito na opinião pública:

a) o Desestímulo à Economia de Mercado provocado pelo Estado de Bem-Estar. Segundo este argumento, o Estado de Bem-Estar retira do mercado os incentivos para investir e empreender;

b) o Alto Custo do Estado de Bem-Estar, provocada pelo rápido crescimento das burocracias e das castas de funcionários públicos, concorre em recursos humanos e econômicos com a iniciativa privada e consome recursos que poderiam ser aplicados na produção industrial não estatal;

c) a Incapacidade de Solução do Estado de Bem-Estar. Um exemplo dos argumentos - que parecem inconsistentes - que os neoconservadores e os neoliberais utilizam em relação a esta incapacidade do Estado de Bem-Estar seria relativo à pobreza, já que, apesar dos recursos destinados ao seu combate, não conseguiu erradicá-la;

d) a Obstrução da Liberdade. Além do risco à Democracia, esta crítica está relacionada também com a impossibilidade da escolha, pelos cidadãos, dos serviços que serão colocados ao seu dispor;

e) a Oposição à Iniciativa Privada, que é produzida como consequência do superdimensionamento do tamanho do Estado. A redução de seu tamanho - para chegar a um Estado Novo Mínimo -, a privatização dos serviços, a contenção do poder dos sindicatos de trabalhadores e a redução da burocracia são as principais propostas que o Neoconservadoriesmo, o Neoliberalismo e a Neotecnocracia apontam como alternativas às políticas típicas do Estado de Bem-Estar.

Porém há outras questões que são apontadas como responsáveis pela crise do Estado de BemEstar e a sua falta de capacidade para atender a suas funções tradicionais:

a) o Estado como protetor não funciona como deveria, já que não consegue evitar a falta de segurança pública, o terrorismo e o surgimento de movimentos anarquistas;

b) o Estado como administrador industrial tem demonstrado sua incompetência. Suas empresas sempre dão prejuízo, sufocam as pequenas e as médias empresas e sacrificam o setor primário da economia; 
c) o Estado como controlador econômico mostra uma política econômica marcada por incertezas e oscilações, com recessão, monetarista e não monetarista, sendo incapaz de evitá-la;

d) o Estado como magistrado está desprestigiado, oferecendo uma justiça lenta e, algumas vezes, corrupta. Não raramente, incorre em inconstitucionalidades evidentes e é refém do corporativismo, tanto público como privado.

Estamos assistindo a talvez a mais grave crise do Estado social, que afeta todas as suas estruturas: políticas, socioeconômicas e jurídicas. Estamos vivendo uma aguda e crítica etapa de transição da civilização ocidental de modo que o Estado, fruto dessa civilização, sofre intensamente essa crise ${ }^{24}$.

Com possivelmente algumas poucas exceções e bem determinadas, será muito difícil o Estado de Bem-Estar Social e seus programas históricos sobreviverem em sua matriz original. ${ }^{25}$ É preciso observar se a força mais ampla da história continuará atuando com a crise iniciada em 2008.

\section{PARA TERMINAR: EM DIREÇÃO À DEFINIÇÃO DE UM NOVO MODELO DE ESTADO NA EUROPA. LIMITES E (PRÉ)CONDIÇÕES}

Fundamentado em tudo o que até aqui foi exposto e discutido, a relação causa-efeito da crise em relação ao Estado de Bem-Estar na Europa aparece como um enredo que não pode ser separado ou desmembrado. O Estado de Bem-Estar e a crise iniciada em 2008 são indissociáveis ${ }^{26}$.

Nessa discussão, deve-se também considerar o fato de que o fundamento constitucional do Estado de Bem-Estar faz parte do núcleo duro do constitucionalismo europeu, como seu pressuposto de fundo para a aceitação de tal modelo de estado de bem-estar. ${ }^{27}$ Mas mesmo assim essa tradição de constitucionalismo social, diante do contexto atual globalizado, sem regras claras de mercado, corre o risco de desintegrar-se em confronto com a voracidade e a rapidez que o sistema econômico mundial impõe aos países ocidentais atualmente. ${ }^{28}$

Diversamente de tudo quanto sucede nos EUA, onde a marginalidade e a disparidade sociais foram sempre dominantes, com a vantagem de um mercado de trabalho muito mais flexível, boa parte dos Estados europeus estão descobrindo graves carências nos serviços sociais, o que é mais complicado quando ligada a uma constante e crescente precariedade no mercado de trabalho. Em outras palavras, a crise econômica, além de acentuar a crise de trabalho, quase zerou o valor "amortizador" social do Estado de Bem-Estar. Segundo os recentes dados fornecidos pela UE, nos países membros cerca de 114 milhões de pessoas, no mês de julho de 2010, estavam no risco de exclusão social: cerca de um jovem entre quatro está ainda à procura da primeira ocupação.

Neste quadro, a Europa aparece extremamente frágil, já que, como se tratou anteriormente, as diversas variantes nacionais do modelo de Estado de Bem- Estar Europeu estão realmente em profunda crise. Ademais, parecem nesta fase prevalecerem os egoísmos nacionais. Estes fatores, valorados conjuntamente, constituem os limites absolutos para o encaminhamento de soluções de curto e médio prazo para a referida crise.

As finalidades da presente reflexão poderão ser úteis, também, em relação ao debate que está envolvendo os principais protagonistas da atual fase histórica, indicando algumas tendências que tentam redefinir o sistema do Estado de Bem-Estar europeu no contexto da crise econômica. ${ }^{29}$

O exercício realizado no presente artigo, como em outras partes também destacado, requer uma capacidade diferente e inovadora de compreender a complexidade, a amplitude e a globalidade dos

24 VERDÚ, Pablo Lucas; MURILLO DE LA CUEVA, Pablo Lucas. Manual de derecho político, p. 117.

25 CRUZ, Paulo Márcio. Soberanía y transnacionalidad: antagonismos y consecuencias, p. 09

26 Sobre isso, recomenda-se seja observada a crítica de FINK, Janet; LEWIS, Gail; CLARKE, John. Rethinking European Welfare, Londres: Cortinew Publications, 2001.

27 Sobre isso ver COUSINS, Mel. European Welfare States, comparative Perspectives. Londres: SAGE Publications, 2005.

28 CRUZ, Paulo Márcio; STELZER, Joana (Org.). Direito e Transnacionalidade. p. 132.

29 Sobre isso ver L. JIMENA QUESADA. A Sustentabilidade dos direitos sociais, Milano, 2011, p. 76 e CAMPEDELLI, M. Na crise, um direito de Welfare?: Entre evidências, direitos e experimentabilidade. Bologna, 2010. p. 594. 
problemas que as autoridades monetárias europeias tentam varrer para debaixo do tapete. Além disso, é necessária também uma nova investida metodológica baseada na interdisciplinaridade de análises entre juristas, sociólogos, cientistas políticos e economistas.

Nesta perspectiva, a construção de um novo paradigma social europeu, que possa ser sustentável, requer algumas (pré)condições imprescindíveis de razoabilidade e justiça, como: a) a redefinição estrutural da organização política da União Europeia, caracterizada por critérios de unidade fiscal (não só monetária); b) a redeterminação dos paradigmas de equidade social; e c) a adoção de instrumentos flexíveis de equilíbrio orçamentário. ${ }^{30}$ Mas se a moderação é a face jurídica da sustentabilidade econômica dos direitos sociais e do próprio Estado de Bem-Estar, a vontade política é a (pré)condição fática sem a qual nada é possível. ${ }^{31}$ Até o momento não há qualquer definição sobre qual projeto político-estratégico a União Europeia realmente adotará. Não está claro se a União Europeia pretende construir uma sociedade indubitavelmente mais austera e sóbria, mas realmente solidária no seu conteúdo e direcionada aos mais necessitados, ou se, em vez disso, pretenda "decidir não decidir", ou seja, perpetuar, em nome da idolatria ao mercado, uma política neoliberal sabidamente inconsistente, permitindo que um sentimento cada vez mais egoísta tome conta de seus membros, o que significa renunciar ao seguinte passo da integração da Europa do tipo $a b$ infra (dentro, abaixo, entre) e a um critério de solidariedade mais forte, que seja $a b$ intra (fora, acima) e que não seja ab extra (distante, longínqua).

Em outras palavras, a situação atual poderia ser definida como um tempo de carência de regras; de ausência de estadistas e líderes europeus e mundiais com estatura suficiente para enfrentar esse desafio; e, como consequência deste panorama, de ausência de adequadas e corajosas escolhas político-legislativas nos diversos níveis nacional e continental, tanto europeu como global.

A austeridade fiscal e os esforços para reduzir salários em países que sofrem estrangulamento monetário podem causar a fratura de sociedades, governos e até dos Estados. Sem uma solidariedade maior, é improvável que essa história termine bem.

Neste contexto, no qual parece prevalecer um conjunto de táticas de curto prazo e típicas dos egoísmos favoritos dos governos nacionais, que sofrem de miopia relativa aos direitos sociais e àqueles referentes às expectativas humanas das gerações futuras, é importante não se deixar de assinalar e/ou considerar a função de suplência subsidiária desenvolvida pela jurisprudência. Emerge, de maneira sempre mais evidente, o relatório decisivo, racional e estratégico dos tribunais nacionais e supranacionais, cuja jurisprudência parece substituir os Parlamentos nesta longa transição sistemática (não somente europeia, mas mundial) cujos êxitos são pouco divulgados.

O dado incontroverso é que o vazio normativo e a ausência de políticas legislativas produziram um fenômeno de reforço normativo do tipo jurisprudencial, a ponto de se poder afirmar que a existência de alguns direitos, não só os sociais, são muito mais fruto de um trabalho de criação judicial do Direito do que movimentos coordenados de governos ou de autoridades europeias. ${ }^{32}$

Substancialmente, além da valoração puramente formalista, ao menos na Europa, o Estado Constitucional Moderno parece adquirir, definitivamente, semblantes de um Estado jurisdicional, profundamente "empapado" de direito supranacional europeu. O que permite especular o embrião de um Estado Transnacional.

Nesse sentido o trabalho dos tribunais europeus, por ter servido como núcleo duro das tradições constitucionais, contribui para alimentar o desenvolvimento de um endereço comum transnacional ${ }^{33}$.

Mesmo que o papel desempenhado pelos tribunais pareça claro, menos compreensível parecem ser as consequências jurídicas sobre a ordem constitucional e as econômicas sobre o tratamento político dado a crise. Na realidade, a possível consequência disso tudo é que os tribunais europeus, apenas atentando ao núcleo valorativo da tradição do constitucionalismo europeu, alcançado por meio de diversas decisões, levem a um modelo de "Estado de Bem-Estar Real", que em realidade está

30 CRUZ, Paulo Márcio; OLIVIERO, Maurizio. Reflexões sobre o direito transnancional, p. 23.

31 CRUZ, Paulo Márcio; FERRER, Gabriel Real. A crise financeira mundial, o estado e a democracia, p. 13.

32 COLAPIETRO, Carlo. A jurisprudência constitucional na crise do Estado Social, p. 46.

33 CRUZ, Paulo Márcio; OLIVIERO, Maurizio. Reflexões Sobre o Direito Transnacional, p. 05. 
sustentado pela estrutura judicial europeia e não positivado. Tudo isso fruto de uma política legislativa descoordenada e, sobretudo, sem uma análise do impacto econômico de tal modelo no tempo (ex ante e ex post), tarefa que deveria ser dos legisladores em suas tarefas decisionais. ${ }^{34}$ Portanto a ausência de debate sobre a sustentabilidade-factibilidade-exigibilidade intensifica o risco e pode produzir um posterior agravamento da relação entre o Estado de Bem-Estar e a crise econômica, com uma definitiva renúncia ao modelo histórico europeu. Já não por opção, mas por necessidade.

Tal risco declinado acima pode assumir dimensões ainda mais complexas. De fato, ou a crise econômica em relação ao Estado de Bem-Estar constitui uma ocasião de relançamento do modelo como oposição à globalização negativa, de segunda oportunidade e de redenção corajosa do sonho e do modelo comunitário ou se revelará o infeliz início do fim do projeto europeu.

\section{REFERÊNCIAS}

BLAS GUERRERO, Andrés; VERDÚ, Jaime Pastor. Fundamentos de ciência política. Madrid: Universidad Nacional de Educación a Distância, 1997.

BOBBIO, Norberto. Dicionário de política. Tradução de Carmen C. Varrialle et al. 6. ed. Brasília: UNB, 1994.

BONAVIDES, Paulo. Do Estado liberal ao Estado social. 6. ed. São Paulo: Malheiros, 1996.

CAMPEDELLI, M. Diritto di welfare: Manuale di cittadinanza e istituzioni social. Bologna: Il Mulino, 2010.

CASTEN, Gustavo. Artigo. A crise financeira internacional. Disponível em: <www.gustavokasten. com>. Acesso em: 24 jul. 2012.

COCCO-ORTU, Ana Maria Lecis. A comparação como método de determinação do modelo de proteção dos direitos dentro do sistema CEDH. Roma: AIC, 2011.

COLAPIETRO, Carlo. A jurisprudência constitucional na crise do Estado Social. Padova: UNISOB, 2009.

CRUZ, Paulo Márcio. Fundamentos do direito constitucional. Curitiba: Juruá, 2001.

. Soberanía y transnacionalidad: antagonismos y consecuencias. Revista de Derecho vLex, Barcelona - Espanha, v. 63, p. 1-10, 2008.

Da Soberania à Transnacionalidade: Democracia, Direito e Estado no Século XXI. Itajaí: Editora da UNIVALI, 2011.

; STELZER, Joana (Org.). Direito e Transnacionalidade. Curitiba: Juruá, 2009.

; FERRER, Gabriel Real. Los nuevos escenarios transnacionales y la democracia asimétrica. Manizales: Revista Jurídicas Universidad de Caldas, v. 7, p. 12-17, 2010.

A crise financeira mundial, o estado e a democracia econômica. Revista da Faculdade de Direito da Universidade Estadual do Rio de Janeiro (UERJ), v. 1, p. 1-23, 2011.

; OLIVIERO, Maurizio. Reflexões Sobre o Direito Transnacional - Itajaí/Perugia. Novos Estudos Jurídicos (On-line), v. 17, p. 18-28, 2012.

CAMPEDELLI, Massimo. Na crise, um direito de Welfare?: Entre evidências, direitos e experimentabilidade. Bologna: Il Molino, 2010.

DALLARI, Dalmo de Abreu. O futuro do Estado. São Paulo: USP, 1972.

FINK, Janet Fink; LEWIS, Gail; CLARKE, John. Rethinking European Welfare. Londres: Cortinew Publications, 2001.

FORSTHOFF, Ernest. Por uma reconstrução da doutrina europeia sobre o uso conceitual do termo e natureza do estado social de direito. Milão: Giuffrè, 1996.

34 RODOTA', Stefano in Nel silenzio della politica i giudici fanno I' Europa in La Carta e Le Corti - I diritti fondamentali nella giurisprudenza europea multilivello, p. 76. 
GIORGIS, Andreas In: CASSESE, Sabino (Org.). Dizionario di Diritto Pubblico. Milano: Editora Universitá Bocconi, 2006. v. III.

JIMENA QUESADA, Luis. A Sustentabilidade dos direitos sociais. In Revista de estudios de economía aplicada, Valencia: Editora Universidad de Valencia, vol. 27-3, 2009.

KING, Anthony; SCHNEIDER, Benton. Teoria política en el Estado de Bien-Estar. Madrid: Alianza, 1993.

MISHRA, Ramesh. O estado-providência na sociedade capitalista. Tradução de Ana Bairradas. Oeiras: Celta, 1995.

NAVARRO, Vicenç. Neoliberalismo y estado de bienestar. Barcelona: Ariel, 1998.

RODOTA', Stefano in Nel silenzio della politica i giudici fanno I' Europa in La Carta e Le Corti - I diritti fondamentali nella giurisprudenza europea multilivello, Taranto: ed. Chimienti, 2007.

SÁNCHES, Jordi et al. Manual de ciencia política. Madrid: Alianza, 1996.

TOUCHARD, Jean. Historia de las ideas políticas. Tradução de J. Pradera. 5. ed. Madrid: Tecnos, 1993.

VERDÚ, Pablo Lucas; MURILLO DE LA CUEVA, Pablo Lucas. Manual de derecho político. Madrid: Tecnos, 2000.

WOLKMER, Antônio Carlos. Elementos para uma crítica do Estado. Porto Alegre: Sérgio Antônio Fabris, 1990. 